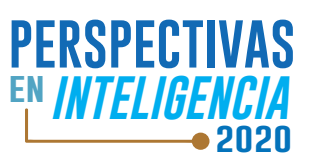

https://doi.org/10.47961/2145194X.220

\title{
El humor gráfico y su valor e importancia histórico-política
}

\author{
Graphic humor and its historical-political value and importance
}

\author{
Pablo Iregui Acosta ${ }^{1}$
}

(1) Pontificia Universidad Javeriana, Bogotá - Colombia, iregui96@hotmail.com

\section{Resumen}

No es ampliamente conocido el valor y propósito real de la caricatura. La ignorancia al respecto implica que el humor gráfico provoque reacciones diversas que pueden resultar en vulneraciones de las libertades civiles. La presente investigación se desarrolló por medio de técnicas de investigación cualitativa, permitiendo encontrar que a lo largo de la historia la caricatura ha sido utilizada de manera extensiva para representar realidades que por su propia naturaleza prefieren ser obviadas, pero que a la postre son testimonio de lo más bajo y perverso de la naturaleza humana. Se concluyó que, si bien el ejercicio artístico del caricaturista requiere regulación, es imprescindible e imperioso proteger su práctica en tanto ha demostrado su valor y utilidad al denunciar de forma cruda y directa esas realidades incomodas o dolorosas.

Palabras clave: Caricatura; crítica; humor gráfico; política.

\section{Abstract}

The value and real purpose of caricature is not popularly known, ignorance about it provokes diverse reactions that may or may not lead to violations of civil liberties. The present investigation was developed by means of qualitative investigation techniques and what was found was that throughout history caricature have been used extensively to represent realities that by their own nature prefer to be ignored, but in the end, are a manifestation of the lowest and perverse of human nature. It was concluded that although the artistic exercise of the cartoonist requires regulation, it's essential as imperative to protect his practice as it has demonstrated its value and usefulness by crudely and directly denouncing those uncomfortable or painful realities.

Keywords: Caricature; criticism; graphic humor; politics. 


\section{Introducción}

La caricatura ha sido objeto de estudio de las ciencias sociales en tanto diferentes disciplinas han dado cuenta de sus alcances, como también de su relevancia cultural y política. En Colombia la caricatura ha jugado un papel fundamental desde que se utilizó por primera vez como recurso de propaganda en apoyo a los esfuerzos de guerra y luchas independentistas. A partir de entonces ha formado parte de la historia de esta nación consolidándose como una poderosa herramienta de control y combate político. Se le reconoce además por su capacidad de impactar en el público receptor a través de un mensaje construido por medio de recursos semiótico-discursivos, simbólicamente representativos de la cultura, tradiciones y vivencias comunes de una sociedad que se siente asimisma identificada y representada.

El presente artículo procura dar cuenta de la utilidad y relevancia del humor gráfico en términos políticos, sociales y culturales, haciendo especial hincapié en los desafíos que conlleva esta práctica artística y política. Para ello es necesario remitirse al trabajo de varios teóricos y expertos del humor político en todas sus manifestaciones, como son Samuel Schmidt o Beatriz González. Es igualmente necesario conducir una revisión histórica del desarrollo de la caricatura como género artístico, desde sus primeras apariciones en la antigüedad, hasta su uso más extensivo en la modernidad y edad contemporánea.

Finalmente se espera, producto de la presente investigación, dejar en claro el propósito de este arte gráfico, revelando su capacidad para acercar a los sectores menos representados de la sociedad a las discusiones más relevantes del debatir político. Se entiende por lo mismo que el caricaturista aspira a que, aún desprovistos de la capacidad de interferir activamente en la política, sus lectores tengan la posibilidad de verse representados por medio de un contenido capaz de generar impacto real en las conciencias de los detentores del poder.

\section{Breve historia de la caricatura y su desarrollo}

La caricatura como medio de representación y distorsión de los actores nace en Europa en el siglo XVII, aunque la sátira y crítica político-social por medio del arte está presente en las sociedades desde los inicios de la civilización occidental. Se sabe que la crítica gráfica tuvo un lugar en los tiempos del Imperio romano, en la manera en la que los habitantes de Pompeya dibujaron la imagen desfigurada de Nerón en los muros de la ciudad, y que estas mismas prácticas acompañaron siglos más tarde el conflicto entre la Iglesia y Lutero. Pudiera entenderse que el objeto de burla y crítica por medio de la caricatura en tiempos de antaño, como en la actualidad son las figuras públicas $y$, más que nada, aquellos que detentan el poder, pero su origen no acarreaba consigo esta intención, pues la caricatura como arte gráfico nace con el propósito de retratar rostros y cuerpos para luego distorsionarlos, o mejor, exagerarlos con el propósito de resaltar atributos característicos. Ya la crítica por medio del arte, y más que nada, la crítica política, vino luego con la aparición de la imprenta y los medios de divulgación masivos (González, 1990; 2009).

Antes de que la caricatura recibiera su nombre, ilustres representantes del Renacimiento ya desarrollaban las técnicas sobre las que se fundaría este género artístico. Entre 
los más reconocidos exponentes de este periodo se encuentran Leonardo da Vinci (1452-1519), Alberto Durero (1471-1528) y Lucas Cranach (1472-1553). Charles Baudelaire, poeta y crítico de arte del siglo XIX identificó, por medio del trabajo de los ya mencionados maestros, dos tipos de caricatura. El primero alude a la representación "grotesca" o exagerada de los atributos físicos de una persona, muy propio de da Vinci, quien encontraba en este tipo de representación una finalidad artística en tanto la exaltación desproporcionada de ciertas características fisionómicas era a su parecer una manera de resaltar lo verdaderamente bello de a quien se dibujaba. Ese mismo enfoque lo retomó Durero, quien se valía de análisis matemáticos para conseguir el mismo resultado (González, 2009; Vega, 2014).

El segundo tipo que identificó Baudelaire es el de la caricatura moderna, cuyo propósito se desliga del meramente artístico para enfrascarse en la crítica ácida y cruda de los aconteceres políticos y sociales. De los primeros ejemplos de este tipo se encuentran, según lo mencionado en un principio, el trabajo de quienes hicieron seguimiento a la Reforma protestante. Entre los artistas que acompañaron este proceso se encuentran Lucas Cranach y Hans Holbein. Cabe aclarar que no sería sino hasta el siglo XVII que la caricatura recibiría este nombre como resultado de la presentación póstuma del trabajo de Annibale Carracci (1560-1609), considerado creador del género. Es así en tanto ya en el siglo XVI existía, previo al concepto de caricatura, el de retratini caricci, o retrato cargado (Vega, 2014).

Al trabajo de Carracci lo siguió el de muchos otros, entre los que se encuentra Jacques Callot (1592-1635), el cual inspirado por las representaciones burlescas, cómicas y grotescas de las máscaras y disfraces de los bailarines del carnaval de Florencia, quiso trasladar esas imágenes al papel y a sus obras. Las ferias populares de los pueblos y localidades italianas eran fuente de inspiración para Callot, y por ello el artista se enfocaba en observar los elementos más humildes que componían las festividades a las que atendía, y a los dibujos inspirados en estos elementos se les pasó a denominar entonces Capriccio. La razón era que el artista se esforzaba por retratar en sus obras ápices de la realidad observada, mezclados con la imaginación propia de quien es su espectador. Desde Italia, el término caricatura llegó a España de la mano del pintor Giambattista Tiepolo (1696-1770), artista al servicio de la casa real de Carlos III y de quien Francisco de Goya (1746-1828) aprendería el arte del capricho al revisar su obra (González, 2009).

De la caricatura derivó la caricatura política, considerada un subgénero artístico de la primera. Si bien el objetivo de la caricatura era producir un efecto hilarante en el espectador a costa de los defectos o atributos del otro en un ejercicio netamente artístico, la caricatura política se pensó como un arma de combate capaz de efectuar una crítica por medio del humor, entendiendo tal vez que "corregir con la risa es la fórmula más civilizada de educar” (González, 1990). La caricatura política nació en las últimas décadas del siglo XVIII y se consolidó del todo en el siglo XIX, luego de que adquiriera preponderancia en la escena social y política de Inglaterra con el trabajo de artistas como James Gillray (1757-1815) y Thomas Rowlandson (1756-1827), y gracias especialmente al desarrollo de las técnicas de impresión como el grabado en metal, la xilografía y la litografía (González, 1990; 2009). 
La caricatura política nace en Inglaterra, pero la conciencia de su poder se originó en Francia. Un ejemplo de ello fue, según lo retrato Stendhal en La cartuja de Parma (1839), el trabajo artístico de un joven soldado - y pintor - de nombre Gross, que calcó en su obra la invasión de Napoleón a Italia, representando al tirano regional de forma caricaturesca, lo que se supone ayudó a su derrocamiento. Aun así, no cabe duda de que la realización del poder político de la caricatura y su descubrimiento en Francia se dio producto del impacto de la obra de Henri Bonaventure Monnier (17991877), caricaturista, escritor y actor que se radicó en Gran Bretaña entre 1822 y 1827 y quien durante su estadía fue testigo del auge de la caricatura en ese país, más que nada debido a las leyes liberales bajo las que se regía la prensa en ese momento. Monnier es considerado como el primer referente en el desarrollo de la caricatura social en Francia, y su obra Escenas populares (1830) es un retrato de ello (González, 1990; 2009).

El mismo año en el que Monnier publicaba sus escenas, Charles Philipon (1800-1862), quien se convertiría en uno de los máximos exponentes de la caricatura social y política en Francia, fundaba su periódico La Caricature. Philipon, que se inició en la práctica del proceso de la litografía, muy reciente en ese entonces y que como ya se mencionó vio sus orígenes en Inglaterra, fundaría también el periódico Le Charivari dos años después. Desde ese último, y con la ayuda de varios grabadores (del metal) que él mismo descubrió, de los cuales el más reconocido fue Honoré Daumier (1808-1879), emprendería una campaña de asedio a las figuras de dos altamente cuestionados y controversiales soberanos: Luis Felipe y Napoleón III, sobrino del conquistador y que aparentemente carecía de todas las cualidades que hicieron reconocido a su tío (González, 1990; 2009).

El trabajo que adelantaron Philipon y su "armada", como se le denominaba al grupo de grabadores que acompañaron su trabajo, y de los cuales hacia parte Daumier, le valió especial reconocimiento y trascendencia por sus caricaturas alusivas al rey Luis Felipe. En ellas se presentaba la metamorfosis del monarca de un ser humano normal a uno con cabeza de pera. Esta, como el resto de las ideas de Philipon, pudo verse materializada únicamente gracias a las litografías que Daumiere produjo, lo que le valieron a este también un reconocimiento, pues se presume fueron las caricaturas las que derrocaron al rey, supuestamente debido a su alcance e impacto social. De las acciones de estos dos ilustres personajes nació la verdad y el mito del poder de la caricatura y su capacidad para derrumbar gobiernos (González, 1990; 2009).

\section{La caricatura moderna: su impacto y los desafíos que plantea a niveles regio- nales e internacionales}

La caricatura como se conoce actualmente, la caricatura editorial, esa que se puede encontrar en diarios y revistas, gacetas y portales web, e incluso en redes sociales como Twitter o Instagram, es el legado del desarrollo histórico de un arte gráfico que ha acompañado a la humanidad durante siglos y que desde sus primeras apariciones ha evolucionado para servir a los propósitos de sus autores. La caricatura como medio para transmitir una crítica y generar control político es la etapa final en la evolución de este tipo de arte, reconociendo el recurso iconográfico como una herramienta de participación política sumamente poderosa. Es así en tanto permite que unos pocos se manifiesten en pro de muchos, que las ideas y pensamientos de quienes no tienen un espacio en las esferas de la alta política resuenen en las mentes de aquellos que 
ostentan tal posición, puesto que este es el fin último de la caricatura y el propósito del caricaturista, hacer uso de su arte para lograr la participación política que de por sí es restringida.

En la literatura que aborda el tema de la caricatura política es común encontrar que los autores hagan mención o aludan al tema del humor político, entendido este como un medio para el ejercicio de la política. Es necesario partir de la base, de acuerdo con los postulados de Schmidt (1992), de que la política en su naturaleza es excluyente y que así mismo también los son los políticos. Ahora, ¿cuál es la idea detrás de este planteamiento? Pues bien, que el poder y la posibilidad de ejercerlo está limitada a unos pocos considerados los más aptos, dada la suposición de que de todos son los más dignos. Las consideraciones filosóficas de las cuestiones morales y éticas que dictaminan tal suposición no competen al tema del presente boletín, es necesario que quien quiera ahondar en estos temas se remita a los textos de Aristóteles, Maquiavelo $\mathrm{u}$ otros varios pensadores que han descrito a profundidad, y según su parecer, las cualidades del gobernante idóneo. No obstante, cabría aclarar que, a consideración del autor del presente documento, tales cualidades se diluyen y escapan de la realidad de lo que son los líderes políticos de la actualidad.

La caricatura política es la manifestación artística del humor político. Ya lo decía Schmidt (1992), después del chiste la caricatura es el medio predilecto para hacer humor. La razón es que como medio de difusión de un mensaje la caricatura tiene la capacidad de alcanzar y permear fácilmente a su receptor debido a lo rápido y sencillo de su lectura. La crítica visceral y en algunos casos inescrupulosa se ve atenuada cuando su entrega se da por medio de un producto fácil de asimilar y con el cual el lector logra sentirse identificado. Esa misma crítica va dirigida a aquellos que detentan el poder, con la intención de que sus comportamientos y las acciones que la suscitaron se vean modificados, producto de la vergüenza. Se espera también que los lectores que no forman parte de la esfera política, pero que sí la estudian o se ven afectados por las decisiones que se toman en su interior, se concienticen y asuman posiciones respecto a lo que se ha representado por medio del arte gráfico.

Los impactos y alcances de la caricatura política son variados y dependen del contexto en el cual se desarrollen. Ejemplo de ello son Estados Unidos y Venezuela, naciones enfrentadas en el sistema internacional por sus discrepancias a nivel político y por la capacidad de desestabilizar una de las regiones donde la otra ejerce injerencia. En ambos contextos, la caricatura ha desempeñado una función específica y las consecuencias de ello han sido a su vez propias de la situación de cada uno de los países. Para elaborar mejor esta idea es necesario remitirse a dos casos puntuales, uno es el de la eliminación total de las viñetas políticas en todas las ediciones del New York Times en EE. UU., y el otro es el papel desempeñado por los caricaturistas y su trabajo en el contexto social y político venezolano.

Los motivos detrás de la decisión de eliminar la viñeta política de todas las ediciones del New York Times fueron de carácter netamente político. En 2019 los directivos del diario neoyorquino se vieron en un predicamento, uno de sus viñetistas publicó una caricatura (figura 1) en la que se representaba al entonces primer ministro israelí, Benjamín Netanyahu, como un sabueso que llevaba puesto un collar con una estrella de David mientras hacía las veces de perro guía del entonces presidente Donald 
Trump, representado como un invidente. La caricatura no solo generó revuelo, sino que el mismo Netanyahu la tildó de antisemita y exigió inmediatamente que fuera removida de toda edición y que el diario ofreciera una disculpa. Los comunicados no se hicieron esperar y el diario lamentó que tal imagen hubiera aparecido en sus páginas. Sin ser esto suficiente, y dadas las repercusiones de esta acción, se optó finalmente por eliminar la viñeta política permanentemente (La Vanguardia, 2019; Chappatte, 2019).

•FIGURA 1. Caricatura de Benjamín Netanyahu en el New York Times

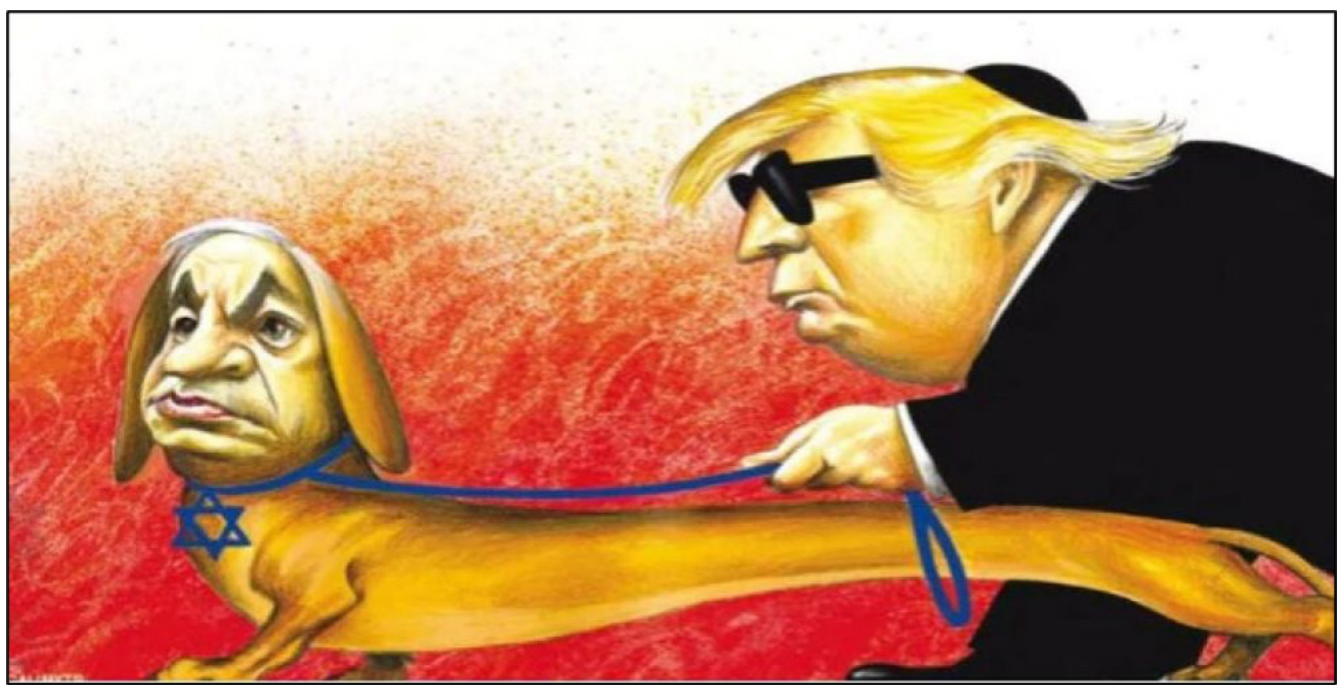

Fuente: LaSexta.com

La decisión del New York Times fue radical y no responde a la lógica del contexto social dentro de la cual funciona el diario, entendiendo que es un periódico estadounidense y que por ende se rige bajo las normas de una democracia, implicando también que goza de todas las libertades propias de este sistema político. Tomando en cuenta que la caricatura alude a dos personajes de por sí controversiales, siendo uno el presidente estadounidense cuya relación con los medios de comunicación fue bastante turbulenta, por decir lo menos, y un primer ministro israelí que ha sido tildado por sus detractores, pero también por medios de comunicación y analistas de la política internacional, como racista y extremista, y conociendo aún más la estrecha relación que ambos líderes han compartido en los últimos años, resulta claro por qué el diario se vio en la penosa situación de eliminar la viñeta política. Solo queda imaginar la presión política e incluso económica a la que posiblemente se pudo ver enfrentado el periódico de no cumplir con las exigencias de Netanyahu.

La libertad de expresión fue cooptada y sin embargo se habla de cómo esto sucedió en el contexto de una democracia, y no cualquiera sino la estadounidense. Netanyahu, por su parte, y desde su posición como primer ministro de Israel, apostó, de acuerdo con el análisis de expertos, por un modelo de democracia iliberal para su país (Ben-Ami, 2019). Aquello implica el respeto de ciertas libertades y derechos fundamentales, a la par que se restringen otros en beneficio del régimen. Si la caricatura hubiera sido publicada 
por un diario israelí, habría tenido sentido el hecho de que se hubiera censurado, pero como la censura se dio consecuencia del capricho y deseo de un líder que ejerce influencia sobre el presidente de la primera potencia del mundo, podría considerarse acertada la manera en la que el caricaturista retrató a ambos mandatarios, uno ciego y completamente desorientado en su postura como líder político con gran poder de injerencia en el sistema internacional, y otro que como un perro fiel que le guía o dirige (aunque a conveniencia) dado que comprende las limitaciones de su dueño.

Diferente al caso del New York Times y lo acontecido en el contexto de la democracia estadounidense, se encuentra el caso de Venezuela y la función que desempeñan los caricaturistas y su trabajo en dicho contexto. Asumiendo que el lector esté enterado de la situación actual del país no será objeto del presente artículo ahondar en el tema, por lo demás se enfocará en explicar cuál ha sido el papel que ha desempañado el humor gráfico en toda esta situación. Cabe resaltar que, a diferencia de lo sucedido con la caricatura de Netanyahu, en Venezuela las caricaturas que representan al presidente Maduro son recurrentes y por ello se considera que no ha sido una preocupación real del Estado detenerlas, o al menos no se ha visto en la capacidad de hacerlo.

Los medios de comunicación al servicio del régimen de Nicolás Maduro, oficiales o afines, se esfuerzan por exaltar las posturas antimperialistas y socialistas características del chavismo. Por el contrario, los medios y cadenas afines a la oposición y sus representantes, siendo una la Cadena Capriles, concentran sus esfuerzos en criticar y ejercer control político sobre la gestión de un régimen que consideran ha sentenciado a Venezuela al destino que hoy enfrenta. En esa disputa se enfrascan artistas como Eduardo Sanabria, conocido bajo el nombre de EDO, un caricaturista crítico del régimen de Maduro, y Vicman, un caricaturista afín al oficialismo y del que no se conoce más. Ambos, bajo su propia visión y estilo artístico, han representado en su trabajo la realidad social y política del país, pero lo han hecho con única intención y es que su discurso acarree un mensaje viciado en contra de todo lo que consideran contrario a sus posturas políticas e ideológicas (Barrón, 2017).

Se mencionaba en el apartado anterior que el propósito de la caricatura política es formular una crítica por medio del humor, en el caso de Venezuela la crítica se ha limitado a un vaivén de ataques en contra de dos sectores políticos cuyas posturas son irreconciliables en tanto el modelo de país que defienden es completamente opuesto. Cuando la crítica no invita a la reflexión y al posible diálogo y solo se limita al desprestigio y el "asesinato de la reputación" de un contradictor político, el único resultado posible es la polarización parcial o total de las bases ciudadanas. Una vez arraigada la polarización en la sociedad, es imposible pensar que la democracia pueda funcionar a niveles óptimos o que siquiera pueda funcionar en lo absoluto, pues los mismos ciudadanos se verán permeados por las posturas ideológicas de las elites en disputa y se replicaran comportamientos excluyentes e incluso violentos entre unos y otros.

Se ha evidenciado cómo la polarización sirve a un propósito electoral en tanto se recurre a la exclusión y confrontación de sectores sociales para consolidar unas bases electorales permanentes que, en el transcurso del tiempo, han sido constantemente bombardeadas con el discurso polarizador de ambos sectores políticos. Fabricar, 
promover y mantener la polarización en una sociedad pasa a convertirse en un recurso para asegurar y obtener votos. El hecho de que esto ocurra en el desarrollo de procesos electorales pone en tela de juicio la validez misma del sufragio y del componente de representatividad. Lo anterior entendiendo que la victoria política de una de las dos partes condena a la otra al destierro parcial o total de la arena política (Lozada, 2004; Bolívar, 2013).

\section{La caricatura política en Colombia y la lucha contra la censura: análisis de los alcances y límites de la libertad de expresión}

Las condiciones que permiten que en Colombia sea posible compartir y hacer crítica política por medio del arte gráfico son las mismas de cualquier otra sociedad fundamentada en valores democráticos, no obstante, es objeto de controversia las afirmaciones de algunos que consideran que el trabajo de caricaturistas y/o viñetistas es utilizado de manera indiscriminada para atacar y destruir la imagen de líderes y figuras representativas de la política. Aseverar que tal es el propósito único de la caricatura, y que por ende es un contenido dañino y carente de todo valor real, resulta problemático y es una idea que defienden solo aquellos que se ven directamente afectados por el mensaje que contiene el humor gráfico. Cabría afirmarse que esos actores que se han visto aludidos en las caricaturas, lejos de comprender el motivo por el cual se los representa (siendo este el replantearse sus propios comportamientos y accionar político) prefieren demeritar el valor intrínseco de la caricatura como medio legítimo de participación política, procurando entonces buscar la forma de acallar la crítica en lugar de afrontarla.

Artistas como Matador y Vladdo, nombres ligados a dos de los más reconocidos caricaturistas del país (si no los más reconocidos), han sido centro de polémicas por su trabajo. Mismo que los posiciona como actores fundamentales de la opinión pública y que por ende están bajo el constante escrutinio de los medios de comunicación y de otros actores igualmente representativos. La atención que se posa sobre ellos se traduce en mayor impacto para sus caricaturas, que no por nada son publicadas en los medios de divulgación masiva más importantes de Colombia. De los dos, el trabajo de Matador ha sido el que en el pasado ha causado mayores revuelos por la crudeza de su humor y crítica. Tal es el caso puntual de la amenaza de muerte que recibió a principios del año 2018 producto de una de sus caricaturas, publicada en plena campaña electoral para las presidenciales y legislativas, y cuya crítica iba especialmente dirigida al candidato del uribismo, fuerza política de gran alcance en el país (Espejo, 2018).

Previo a la amenaza, Matador fue objeto de una demanda de tutela por parte de un ciudadano afín al uribismo, lo mismo producto de los pronunciamientos de la cabeza de esta fuerza política, Álvaro Uribe Vélez. El entonces senador habría afirmado que el trabajo del caricaturista viciaba a la opinión pública en contra del candidato que su partido presentaba a elecciones, y lo hacía por medio de la mofa y ridiculización de su imagen, deslegitimándolo a él y a los sectores políticos que representaba. La tutela por sí sola pretendía disuadir a Matador de utilizar su posición como figura pública y miembro activo de la prensa para atacar a uno de los candidatos en contienda, lo cual por sí solo es válido entendiendo que en Colombia existen leyes que rigen el quehacer de las campañas electorales, como la Ley 130-94, en la cual se estipula por qué medios, en qué tiempos y utilizando qué recursos se pueden adelantar dichas campañas. Lo 
verdaderamente problemático de toda la situación es que las acciones emprendidas en contra de Matador y su trabajo hayan escalado de una acción legal a una amenaza de muerte.

El caso del caricaturista colombiano pone en perspectiva la cuestión sobre los alcances y límites de la libertad de expresión. Si algo ha quedado claro en el desarrollo del presente artículo es que el ejercicio de la política por medio de la caricatura es casi tan antiguo como la formación de los estados-nación. Su aparición estuvo ligada a la imposibilidad de quienes no pertenecen a la élite gobernante de participar e influir de manera activa en las decisiones políticas. Los efectos de la caricatura sin embargo no deben ser tomados a la ligera, su capacidad de influir sobre los receptores es una herramienta que puede ser utilizada con muchos fines, y por esa misma razón resulta necesario plantearle límites al ejercicio de esta práctica, procurando que estos no violen la libertad de expresión en ningún sentido pero que tampoco permitan que bajo esa mirada se pueda transgredir otras libertades, normas o leyes.

\section{Revisión y análisis histórico del humor gráfico utilizado con fines militares}

Producir caricaturas no es un ejercicio restringido a unos pocos que han hecho de este un medio para participar en política. El uso extendido del humor gráfico en otros ámbitos y por diferentes autores habla bien de su versatilidad y cómo este contenido se adapta a las necesidades del autor y su público. Las diferentes expresiones del humor por medio de la caricatura, vinculadas al ejercicio y prácticas militares, cumplen una función un tanto diferente a la de la caricatura o viñeta editorial, dado que la crítica, o mejor, el mensaje que pretenden difundir los medios militares que hacen uso de estas, sirve a varios fines. Uno, siendo el atacar de forma no convencional una amenaza que represente un riesgo real al aparato estatal que defienden; otro, el representar por medio de este contenido valores propios de la institución militar y su trabajo.

El uso extendido de la caricatura en el contexto de la guerra anglo-zulú de 1879 sirve a manera de ejemplo ilustrativo sobre el uso que la institución castrense le ha dado al humor gráfico. En el contexto de la guerra que el Imperio británico libró con la nación zulú por territorios comprendidos dentro de lo que actualmente se conoce como Sur África, la caricatura que los medios de divulgación masiva de la época producían iba encaminada a desdibujar la imagen del Rey Zulú Cetewayo (c. 18261884) representándolo como un salvaje primitivo, aun cuando los mismos británicos demostraban admiración por las proezas militares de su ejército. Al respecto vale la aclaración de que las caricaturas no se produjeron al interior o por miembros de las fuerzas militares, sino por parte de los medios que pretendían apoyar el esfuerzo de guerra (Anderson, 2008).

Los resultados del conflicto con los zulús, y la posterior visita del Rey Cetewayo a Inglaterra para reunirse con la Reina Victoria (1819-1901), evidencian un cambio en la línea editorial de los diarios y gacetas de la época que pasaron de retratar a un rey barbárico y salvaje a uno refinado, civilizado y que incluso se acoplaba bastante bien a las costumbres y modales ingleses. Esta situación dio paso a la configuración de nuevos estereotipos e imaginarios colectivos sobre los pueblos africanos y sentaría un antecedente que retumbaría en el desarrollo de otras campañas militares para restablecer o mantener el control colonial (Anderson, 2008). 
Un ejemplo mucho más explícito del uso militar de la caricatura, en tanto fue utilizada directamente por militares con un propósito específico, es el de la expedición astronómica de 1874 a las islas Sándwich para observar el tránsito de Venus. Ingeniada y liderada en su mayoría por oficiales navales y del ejército, la expedición fue documentada de manera ingeniosa por medio de caricaturas que el hasta hace poco desconocido teniente de la Royal Marine Artillery, Evelyn James Wheelock Noble (1849-1896), dibujó. El propósito del viaje, más allá de su valor científico, era reafirmar el poderío militar británico. No es coincidencia que la expedición tuviera como objeto a Venus, que representaría a los "ejércitos de la ciencia", y no por el contrario a Marte, que serviría para representar a los "ejércitos de la conquista". Demostrar que el imperio británico dominaba cualquier campo, fuera el de batalla o el del conocimiento, era la idea que se ocultaba detrás de dicha lógica (Higgitt, 2017).

Con la expedición a las islas se logró enaltecery exaltar los valores militares dela gallardía y masculinidad propias de los hombres que forman parte de las fuerzas militares. Y fue así en tanto las caricaturas de Noble retrataban las cualidades del militar que es capaz de enfrentarse a las adversidades que le representan una expedición en terreno agreste, su disciplina para cumplir con sus obligaciones y, más aún, la templanza necesaria para realizarlas bajo presión. A esto se suma la idea de que el soldado, a diferencia del científico, está acostumbrado a servir en compañía de solo hombres, por lo cual en la caricatura Noble representaba el carácter del soldado que coquetea, mas no sucumbe a sus pasiones, aún en presencia de mujeres u otras distracciones, durante el cumplimiento de su deber (Higgitt, 2017).

La relación adúltera que el almirante Nelson (célebre oficial naval británico) sostuvo con Emma Hamilton, y cuyo fruto fue el hijo ilegítimo de la pareja, dio cabida al inusual uso de la caricatura en el ámbito militar. El humor gráfico jugó un papel fundamental en la manera en la que la sociedad civil y militar asimiló y juzgó la relación de Nelson con la dama Hamilton. James Gillray, quien sería el encargado de representar a la pareja del almirante en sus caricaturas, adoptaría posturas encontradas conforme se desarrollaba la relación bajo la mirada de la opinión pública. En sus primeros dibujos retrataba de manera benévola a lady Hamilton, considerada en un principio víctima de todo este escándalo. Luego, a medida que avanzaba el tiempo y ante la negativa respuesta de la sociedad londinense respecto a la manera en la que Nelson manejó su relación, pasó a representarse a Hamilton como una oportunista que buscaba únicamente aprovecharse de la posición del almirante como figura pública y militar (Lincoln, 2015).

En el trabajo de Gillray es posible evidenciar el cambio narrativo que permitió la introducción del componente machista que constituía parte del imaginario colectivo de la sociedad londinense de esa época. A lo anterior se contrapone la masculinidad de Nelson, cualidad de la que se premia cualquier militar, sobrevalorada y enaltecida en tanto sus acciones y responsabilidad en la relación nunca fueron cuestionadas o reprochadas de la misma forma en las que sí fueron las de Emma Hamilton. Lo pérfido de la moral occidental, europea en todo caso, se puso en evidencia en la medida en que se juzgó y sentenció por el único placer que profiere el deseo de dominación propio de quienes solo pregonan desprecio por todo lo carnal y terreno, todo cuanto es propio de la vida misma. Actitudes que se mantienen presentes en la realidad actual de las sociedades contemporáneas. 
El valor de la caricatura, y por ende del humor gráfico, ha sido subestimado en el ámbito político y militar, así lo considera Bredekamp (2007), quien resalta la importancia de estos contenidos a partir de los planteamientos de Hobbes (1588-1679). Para el filósofo inglés las imágenes, el dibujo y en ese sentido la caricatura, eran recursos poco considerados, aunque sumamente útiles como medios para el ejercicio del poder y control del público receptor. Para Bredekamp un ejemplo del uso adecuado de estos recursos fue precisamente la ilustración de portada que acompañó la primera edición publicada de la afamada obra de Hobbes, el "Leviatán". Para el primero, la sola imagen capturaba de forma ingeniosa los postulados e ideas que el filósofo proponía en su trabajo. La figura del Leviatán, la terrible criatura mitológica que hace su aparición en la Biblia, es una representación alegórica que simboliza el poder del Estado inglés y la comunión de este con la Iglesia para formar esa gran bestia fundamentada bajo la idea de la seguridad que deriva del pacto o contrato social. Una imagen poderosa puesto que de entrada está exponiendo al lector cuál es el argumento central de la obra.

El Estado es tan poderoso como lo son sus fuerzas armadas, potenciarlas por todos los medios es una tarea por lo demás obligatoria. La creación de carteles, historietas, pero también de caricaturas, como las utilizadas para soportar el esfuerzo de guerra estadounidense durante la Segunda Guerra Mundial, son claros ejemplos de ello. Cuando esos mismos contenidos son utilizados para atacar a las instituciones, pasan a ser considerados un problema. Ejemplo de lo anterior es el material propagandístico producido durante las décadas de 1960 y 1970, dentro del que se incluyen las caricaturas, y que soportó todas las movilizaciones y movimientos que abogaban por el respeto y la garantía de los derechos civiles en Estados Unidos y Francia, sumado a las manifestaciones en contra de la guerra de Vietnam y a la intervención extranjera en el sudeste asiático.

Lo que se ha escrito desde la academia a propósito del impacto y poder de las imágenes establece que los recursos iconográficos suelen tener mayor impacto que un análisis riguroso expuesto por otros medios. Al respecto se ha establecido también que los formuladores de opinión u "opinion shapers" han jugado un papel fundamental en la manera en la que son percibidos los líderes militares, especialmente en países como Estados Unidos. En el transcurso de la historia de ese país el antimilitarismo fue adquiriendo relevancia a la par que pensadores con tendencias antimilitares ganaban influencia. Durante el siglo XX hubo periodos de apaciguamiento de las críticas en contra de los líderes militares, especialmente en el periodo entre guerras, pero se vieron nuevamente azuzadas durante el conflicto en Vietnam y posteriores. La academia en ese tiempo asumió posturas mucho más críticas en cuanto a la validez de la caricatura como recurso fidedigno para la formulación de conocimiento frente a los hechos que representaba. Lo mismo permitió que los conceptos "antiguerra" y "antimilitar" fueran diferenciados. El primero comprende toda postura contraria a la promulgación y el desarrollo de conflictos bélicos, mientras que el segundo se refiere a posturas que reniegan radicalmente de la existencia de líderes militares o de la misma milicia por considerarlos entes malignos al servicio de los intereses de unos pocos (Kemble, 2007).

Se mencionaba que la academia asumió posturas mucho más críticas respecto al valor de la caricatura como fuente de conocimiento, aquello significó el reconocimiento del valor de este contenido a lo largo de la historia como un medio útil para expresar e inculcar ideas, pero también para educar al público receptor. Ejemplo de esto eran las caricaturas que se publicaban en las revistas británicas de emisión semanal Punch y London Charivari. Ambos medios fueron muy reconocidos en Inglaterra durante las 
décadas de 1840 y 1850 por la emisión de caricaturas abolicionistas que pretendían no solo retratar sino también ilustrar al público en términos de la crueldad que conllevaba la perpetuación de la esclavitud en Norteamérica. Caricaturas de esa época como la de John Tenniel, titulada "La esclava de Virginia", en la que se representaba a una mujer de color desnuda, fue publicada en Punch en el año 1851. La misma fue utilizada por William Wells Brown como respuesta a la estatua "El esclavo griego" de Hiram Power, considerada por Wells como un intento de whitewashing del proceso esclavista en África (Chaney, 2010).

La caricatura y la visualización que obtuvo gracias a Wells Brown y su ejercicio didáctico en rechazo a la que consideró una obra negacionista del proceso esclavista africano, le significaron a Tenniel un rechazo generalizado por parte de la sociedad burguesa del momento, que por lo demás no tardaría en pronunciarse al respecto de su trabajo. Pero antes de que eso llegase a ocurrir fue primero emitida una editorial del diario National Era en la que se acordaba el valor pedagógico de las caricaturas del Punch. En esta se referían a las caricaturas como "profesores pictóricos" cuya vena artística revelaba verdades humanizadas que debían ser preponderadas con vergüenza y no con resentimiento (Chaney, 2010).

La editorial del National Era, en apoyo a la revista y al caricaturista, revela desde entonces el valor intrínseco del humor gráfico y la sátira, en tanto se espera que su contenido incomode de tal manera al personaje o grupo al que se dirige la crítica que este se vea obligado a replantearse y ojalá a cambiar el comportamiento que suscitó la crítica en primer lugar. La misma idea se replica en otros contextos, como el papel que jugaron la caricatura y otras expresiones artísticas en la resistencia pacífica que se emprendió en contra de las dictaduras militares de Brasil (1964-1985) y Argentina (1976-1983).

En el caso de Brasil la caricatura fue el medio para denunciar la violación de las libertades civiles y derechos fundamentales que fueron vulnerados de la mano de las fuerzas militares y de represión. En el caso argentino la caricatura solo fue una de las muchas manifestaciones artísticas cuyo impacto trascendió de la resistencia a la lucha, especialmente porque en el "proceso", como se le denominó al periodo dictatorial argentino, las fuerzas militares pretendieron por medio del arte gráfico y otros recursos, recrear o, mejor dicho, construir un pasado imaginario con el que pretendían exaltar valores militares que no eran propios de la sociedad argentina. La respuesta no se hizo esperar y vino de la mano de algunos actores tales como Charly García, uno de los representantes más significativos de la resistencia pacífica quien, aunque no era caricaturista, sí pudo combatir la maquina represiva de la dictadura con la propia, la del Rock n' Roll (Schneider, 2015; Wilson, 2015).

\section{Conclusiones}

La caricatura, específicamente la caricatura política, debe ser entendida como una herramienta de participación política en tanto le permite a su autor expresar opiniones, críticas e ideas por medio del humor y la sátira. Por la rapidez y la facilidad con la que se lee este tipo de contenido se sabe que tiene especial poder de influencia sobre su público receptor en tanto este asume posturas y formula opiniones concernientes a los aconteceres políticos y sociales basado en el mensaje recibido y asimilado. Suelen 
ser objeto de críticas las élites políticas, sociales y en general, todos los detentores del poder. Es así que en tanto la naturaleza excluyente de estos actores previene que un amplio sector de la sociedad interactúe directamente con ellos, resultando en la poca o nula representatividad de los intereses de la mayoría en la arena política.

El humor gráfico debe ser estudiado con detenimiento y especial cuidado puesto que, si bien el ejercicio del caricaturista está amparado bajo las leyes y libertades democráticas, el mismo puede incurrir en prácticas que signifiquen una transgresión a las normativas legales bajo la concepción errada de que la libertad de expresión lo protege o incluso lo exime de acatar dichas normas. A pesar de esto, no se debe cooptar el trabajo del caricaturista en tanto se ha hecho evidente que su arte ha sido una herramienta de combate político efectivo e incluso necesario en tiempos de represión y dictadura. Restringir el humor no tiene cabida ni tampoco motivos, se requiere únicamente que el artista considere los alcances de su obra y por lo mismo regule su divulgación en la medida en que el contexto y la situación lo requieran.

\section{Referencias}

Anderson, C. (septiembre de 2008). A Zulu King in Victorian London: Race, Royalty and Imperialist Aesthetics in Late Ninteenth-Century Britain. Visual Resources, 24(3), 299-319. https://doi.org/10.1080/01973760802284661

Barrón, A. (2017). El humorismo gráfico como reflejo de la polarización en Venezuela: un estudio de las caricaturas de Edo y Vicman desde el análisis crítico del discurso multimodal. Gláuks: Revista de Letras e Arte, 17(1), 144-169.

Ben-Ami, S. (12 de abril de 2019). Israel redobla la apuesta a la democracia iliberal. Clarín. Obtenido de https://www.clarin.com/opinion/israel-redobla-apuestademocracia-iliberal_0_BPcQx-Mih.html

Blanco, J. A., Rojas, R., Aragón, U. d., \& Faya, A. J. (2011). El otro paredón: asesinatos de la reputación en Cuba. Eriginal Books.

Bolívar, A. (2013). La construcción discursiva de la revolución bolivariana. Polarización y manipulación en la campaña electoral de 2012. Temas de Coyuntura(67), 131163.

Bredekamp, H. (2007). Thomas Hobbes's Visual Strategies. En P. Springborg (Ed.), The Cambridge Companion of Hobbes's Leviatan (págs. 29-60). Cambridge University Press. https://doi.org/10.1017/CCOL0521836670.002

Buijzen, M., \& Valkenburg, P. M. (mayo de 2004). Developing a Typology of Humor in Audiovisual Media. Media Psychology, 6(2), 147-167. https://doi.org/10.1207/ s1532785xmep0602_2

Chaney, M. (2010). Heartfelt Thanks to Punch for the Picture: Frederick Douglas and the Transnational Joework of Slave Caricature. American Literature, 82(1), 57-90. https://doi.org/10.1215/00029831-2009-069 
Chappatte, P. (2019). El fin de las viñetas políticas en el New York Times. Letras libres. Obtenido de https://www.letraslibres.com/espana-mexico/politica/el-fin-lasvinetas-politicas-en-el-new-york-times

Espejo, G. (24 de julio de 2018). Uribe vs Matador: las nuevas críticas del expresidente por una caricatura. Obtenido de LAFM: https://www.lafm.com.co/politica/uribe-vsmatador-las-nuevas-criticas-del-expresidente-por-una-caricatura

Gárate, M. (6 de octubre de 2015). El nacimiento de un monstruo. Amérique latine: mémoires et histories nationales(104), 87-104. Obtenido de https://journals. openedition.org/caravelle/1588 https://doi.org/10.4000/caravelle.1588

González, B. (1990). La caricatura política en Colombia. Credencial historia(10). Obtenido de https://www.banrepcultural.org/biblioteca-virtual/credencialhistoria/numero-10/la-caricatura-politica-en-colombia

González, B. (2009). La caricatura en Colombia a partir de la independencia. Obtenido de https://www.banrepcultural.org/la-caricatura-en-colombia/texto01.html

Higgitt, R. (2017). Framing the transit: expeditionary culture and identities in Lieutenant E.J.W. Noble's caricatures of the 1874 transit of Venus expedition to Venus. Annals of Science, 1-26. https://doi.org/10.1080/00033790.2017.132807 4 PMid:28573911

Kemble, R. (octubre de 2007). Mutations in America's Perceptions of Its Professional Military Leaders. Armed Forces \& Society, 34(1), 29-45. https://doi. org/10.1177/0095327X06293862

laSexta.com. (2019). La caricatura de Trump y Netanyahu que ha acabado con las viñetas politicas en The New York Times. Obtenido de https://www.lasexta.com/noticias/ cultura/caricatura-trump-netanyahu-que-acabado-vinetas-politicas-the-newyork-times_201906125d00df390cf21df7ccbf2f0f.html

Lincoln, M. (2015). Emma Hamilton, war, and the depiction of feminity in the late eighteenth century. Journal of Maritime Research, 17(2), 135-145. https://doi.org $/ 10.1080 / 21533369.2015 .1094983$

Lozada, M. (2004). El otro es el enemigo: imaginarios sociales y polarización. Revista Venezolana de Economía y Ciencias Sociales, 10(2), 195-209.

Meyer, J. C. (agosto de 2000). Humor as a Double-Edge Sword: Four Functions of Humor in Communication. Communication Theory, 10(3), 310-331. https://doi. org/10.1111/j.1468-2885.2000.tb00194.x

Redacción. (2019). New York Times dejará de publicar viñetas políticas tras polémica antisemita. La Vanguardia. Obtenido de https://www.lavanguardia.com/ vida/20190611/462809713631/new-york-times-dejara-de-publicar-vinetaspoliticas-tras-polemica-antisemita.html 
Schmidt, S. (1992). Humor y política en México. Revista Mexicana de Sociología, 54(1), 225-250. https://doi.org/10.2307/3540785

Schneider, T. C. (septiembre-diciembre de 2015). The opposition to the Brazilian dictatorship abroad through cartoons and caricatures (1964-1979). História Unisinos, 19(3), 358-367. https://doi.org/10.4013/htu.2015.193.07.e

Taylor, D. F. (2015). Gillray's Gulliver and the 1803 Invasio Scare. En D. Cook, \& N. Seager (Edits.), The Afterlives of the Eighteenth-Century Fiction (págs. 212-232). Cambridge University Press. https://doi.org/10.1017/СBO9781107294424.011

Vega, A. (11 de diciembre de 2014). Caricaturas: los genios también exageran. Obtenido de artelista blog: https://www.artelista.com/blog/caricaturas-los-geniostambien-exageran/

Wilson, T. (2015). Un pájaro progresivo: Pop Music, Propaganda, and the Struggle for Modernity in Argentina. Studies in Latin America Popular Culture, 33, 89-107. https://doi.org/10.7560/SLAPC3307 